\title{
The Complexity of Technological Innovation Decision-Making in Emerging Industries
}

\author{
Wenjing Li $\mathbb{D}^{1,2}$ Xue Guo $\mathbb{D}^{1,2}$ and Dan Cao ${ }^{10}{ }^{3}$ \\ ${ }^{1}$ School of Economics, Wuhan Textile University, Wuhan 430200, China \\ ${ }^{2}$ Center of Industrial Economy, Wuhan Textile University, Wuhan 430200, China \\ ${ }^{3}$ School of Business Administration, Zhejiang Gongshang University, Hangzhou 310018, China \\ Correspondence should be addressed to Dan Cao; cd@mail.zjgsu.edu.cn
}

Received 14 May 2021; Revised 5 July 2021; Accepted 12 July 2021; Published 31 July 2021

Academic Editor: Baogui Xin

Copyright (c) 2021 Wenjing Li et al. This is an open access article distributed under the Creative Commons Attribution License, which permits unrestricted use, distribution, and reproduction in any medium, provided the original work is properly cited.

\begin{abstract}
It is well known that innovation-driven emerging industries have gradually become the main driving force of global economic recovery and growth. Technological innovation decision-making is a complex and dynamic system, which is affected by various factors inside and outside an enterprise. In this dynamic system, how to make the optimal technological innovation investment decisions is a key concern for enterprises and governments. As an investment activity, technological innovation largely depends on the amount of external financing obtained by enterprises. However, financial constraints have increasingly become an obstacle to enterprises' technological innovation. At the same time, technological innovation is also affected by the external political and economic environment, such as changes in economic policy, government subsidy policies, and institutional environmental policies. Can these external environments reduce the negative impact of financing constraints on technological innovation? In this study, based on the data of listed companies in China's strategic emerging industries, we adopt a panel negative binomial regression model to investigate the complexity of technological innovation decision-making from the perspective of financing constraints. Our main findings include the following. First, financing constraints significantly inhibit the input and output of technological innovation in emerging industries. Second, the inhibition effect on the output of substantive innovations is more pronounced than that on the output of strategic innovations. Third, based on the analysis of enterprise heterogeneity in different dimensions, we show that this inhibition has a selective effect among different industries. Finally, we show that economic policy and marketization can help alleviate the inhibition effect of financing constraints on technological innovation.
\end{abstract}

\section{Introduction}

Innovation is a key issue of economic development and has become a driving force for high-quality development [1]. Innovation can bring more efficient technologies and promote social development [2]. No high-quality development is possible without the important supporting role of technological innovation. Furthermore, strategic emerging industries is the key forces of technological innovation. The cultivation and development of strategic emerging industries are of great practical significance for building a modern economic system and realizing high-quality economic development $[3,4]$.

As an important investment activity, technological innovation is inevitably affected by a variety of factors inside and outside an enterprise. One is from the internal perspective of the enterprise, such as its nature, property rights, governance structure, strategy, equity incentives, size, age, investment strategies, and financial constraints. The other is from the external perspective of the enterprise, such as economic policy uncertainty and marketization process. In fact, technological innovation depends 
to a large extent on the amount of external financing an enterprise can secure. The external political and economic environment influences its financing constraints and ultimately affects its technological innovation decisionmaking. How to effectively incorporate internal and external factors when studying the dynamic decision-making of enterprise technological innovation will be the focus of this article.

Technological innovation activities cannot be separated from the support of financing. The $R \& D$ and innovation activities of enterprises depend to a large extent on whether they can obtain sufficient external equity financing and debt financing $[5,6]$. In the face of large investments in technological innovation, the biggest obstacle faced by enterprises is capital constraints. Many technological innovation projects are subject to capital constraints and eventually are shelved. In a perfect capital market, information is completely symmetrical and there are no transaction costs and financing costs, so companies can easily raise the funds from the capital market. However, there are often financing constraints in the actual capital market due to information asymmetry, moral hazard, and adverse selection, which increase the cost and difficulty of external financing for enterprises. Compared with general investment, the information asymmetry in technological innovation is more severe. Moreover, technological innovation requires a greater amount of investment and longer R\&D cycle. As a result, it is more difficult for enterprises to obtain external financing for technological innovation. This can cause serious financing constraints. Then, do financing constraints affect the company's technological innovation decisions? Is this effect related to enterprise and industry characteristics? How do economic policy environment and marketization work under such effect? In this study, we aim to analyze these problems. Our results can provide theoretical support for building a financial system suitable for technological innovation and providing guidance for better implementing the innovation-driven development strategy.

In this study, we exploit the listed companies in China's strategic emerging industries over the period 2009 to 2019 to study the decision-making of technological innovation in emerging industries. We focus on strategic emerging industries because these industries are the main forces in technological innovation.

Given that technological innovation is also affected by the external political and economic environment, such as economic policy fluctuations, and institutional environmental policies, whether these external environments can minimize the negative effects of financing constraints on technological innovation, stimulate enterprises' investment in technological innovation, and enhance enterprises' technological innovation capability is also a key aspect of national policy attention. Hence, we add economic policy uncertainty and marketization environment variables as the moderator to test whether they can alleviate financing constraints on technological innovation. Our findings do indicate economic policy uncertainty and marketization can weaken the negative effects of financing constraints on technological innovation. Specifically, the higher the marketization, the smaller the inhibition effect, and the greater the uncertainty of economic policy, the smaller the inhibition effect of financing constraints on technological innovation.

In this study, we make three major contributions. Firstly, in the literature, most scholars analyzed the financing constraints through investment-cash flow sensitivity based on the idea of Fazzri et al. [7]. However, more recent studies found that the investment-cash flow sensitivity has its own drawbacks. In this study, financing constraints index (referred to as FC in the text) is constructed through a series of financial indicators to measure the financing constraints, which are then incorporated into the overall analytical framework of technological innovation as an influencing factor. Secondly, the influence of financing constraints on technological innovation is studied from both the input and output of technological innovation. In particular, we analyze the impact of financing constraints on the innovation output of different types (strategic innovation and substantive innovation). It is found that the inhibitory effect of financing constraints on substantive innovation, such as invention patent, is more pronounced than that of strategic innovation. Thirdly, we reveal the roles of economic policy uncertainty and the marketization in regulating the negative correlation between financing constraints and technological innovations. This helps to realize the connection of the microbehaviour and macro policy and provide the microevidence at the enterprise level on how the macropolicy drives the investment.

The rest of the article is organized as follows. Section 2 presents a literature review; Section 3 develops the research hypotheses; Section 4 discusses the data and methodology, including sample selecting, procedure, data sources, and model specification; and the empirical results and related discussions are described in Section 6. Finally, Section 2 presents the conclusion and policy implications.

\section{Literature Review}

Innovation and financial development are both core factors affecting sustainable development of economy. In the 21 st century, technological innovation plays a more important role in the country's comprehensive competitiveness, while financial constraints also become an increasingly serious obstacle in the process of enterprise development. In this context, scholars began to focus on the impact of financial development on the technological innovation of enterprises. The literature generally affirmed the promoting effect of financial development on technological innovation $[8,9]$. However, there was no consensus on the mechanism of financial influence innovation. One view held that financial development promotes technological innovation by alleviating financing constraints faced by enterprises, that is, reducing financing costs and broadening financing channels $[10,11]$. The other view maintains that financial development boosts technological innovation by improving the 
efficiency of capital allocation [12]. These studies focused on the relationship between financial development and technological innovation from a macroperspective and do not explore its micromechanism in more detail. However, technological innovation is always the behavior of enterprises at the microlevel. The transmission mechanism of financial development to technological innovation still needs to be investigated on the motivation and specific behavior of enterprises.

As information economics took off, scholars began to study financial constraints under the condition of information asymmetry. Since Fazzari, Hubbard, and Petersen first proposed to measure the financing constraints using the investment-cash flow sensitivity [7], this method was subsequently extended to research and development investment and other investment fields to seek stronger theoretical support of financing constraints from the perspective of cash flow. On the basis of this theory, a large number of scholars discussed the relationship between financing constraints and technology innovation investment from the perspective of the cash flow. However, there were great differences in the development of capital markets and innovation investment in various countries. When different countries were used as samples to study the relationship between financing constraints and technological innovation, there were some differences in the conclusions. Hall believed that it is precisely because of the difficulties in raising funds from outside for innovation investment that companies mainly rely on internal financing for innovation [13]. Hall, Himmelberg, and Petersen, and He studied American companies and found a strong positive correlation between R\&D investment and cash flow sensitivity [14-16]. Mulkay et al. held that the sensitivity of innovation investment to cash flow in the United States is more pronounced than that in France and Japan [17]. Harhoff showed that there is a statistically significant but weak relationship between $\mathrm{R} \& \mathrm{D}$ investment and cash flow of German companies [18]. Bond and Harhoff held that there is no significant relationship between $R \& D$ investment and cash flow in German and the UK [19]. Bloch believed that R\&D investment expenditures of Danish companies are significantly affected by internal cash flow, and R\&D investment has investment-cash flow sensitivity [20].

With the advancement of technology and the expansion of production scale, it is difficult to meet the capital needs of enterprises solely by relying on internal financing for projects with large investment such as technological innovation, and external financing has gradually become the main financing channel for technological innovation. Researchers began to focus on the financing constraints of technological innovation from the perspective of external financing. External funds for R\&D projects are believed to be relatively scarce, mainly due to the serious information asymmetry in the financing process. The uncertainty and strategic nature of $R \& D$ may restrict managers from disclosing relevant information about $\mathrm{R} \& \mathrm{D}$ projects to external investors in order to prevent the information from being known to competitors [21-23].
Hall pointed out that despite the adoption of measures such as intellectual property protection, government subsidies, and tax incentives, technological innovation investment is still difficult to finance or the financing cost is high. There is often a big gap between the rate of return required by enterprises to use their own capital and the rate of return required by outside investors, which leads to the high cost of external capital, and some innovation projects cannot even be financed from outside [24]. Brown and Petersen believed that the output of innovation activities is characterized by nonexclusive indivisibility and uncertainty, leading to the social optimal investment level much higher than the private optimal level, which seriously hinders the enterprises from using all the internal funds for R\&D [25]. Li held that, compared with general investment, $\mathrm{R} \& \mathrm{D}$ investment is more inflexible, and R\&D-intensive companies facing financing constraints are more likely to pause or cut off $\mathrm{R} \& \mathrm{D}$ projects. The risk of R\&D-intensive companies increases with the degree of financing constraints [26]. Mina et al. believed that the uncertainty of innovation activities have a negative impact on financial supply, which is related to the expectation of enterprises to take risky projects, leading to higher external capital costs and possible access to suboptimal external financial resources [27].

In addition to the internal characteristics of the enterprise, the external environment will inevitably have an impact on innovation decisions. Relevant literature concentrates on research from the perspective of economic policies, government subsidies, and marketization. There are two views on the impact of economic policy uncertainty on technological innovation. One view is that economic policy uncertainty can have an incentive effect on technological innovation. This is because economic policy uncertainty represents an opportunity to increase revenue in the future [28]. Under the motive of pursuing profit, uncertainty is beneficial to enterprises to increase R\&D investment [29]. The other view, based on the analysis of the physical budget theory, believes that the uncertainty of economic policies inhibits the technological innovation [30]. Regarding the effect of marketization, most scholars have affirmed the role of marketization in the process of technological innovation and believed that the improvement of marketization is generally conducive to promoting technological innovation [31-33]. Nonetheless, no consensus has been reached on which systems play a role in promoting technological innovation.

When studying the impact of financing constraints on technological innovation, most scholars only focused on innovation input and rarely paid close attention to the impact of financing constraints on technological innovation output. However, technological innovation output is the key to promote the development of social productivity, especially substantive innovation (invention patents). Therefore, the impact of financing constraints on technological innovation output is worth of social attention. In view of the above considerations, the impact of financing constraints on technological innovation should be extended from technological innovation input to technological innovation output, aiming to 
comprehensively analyze the impact of financing constraints on technological innovation activities in strategic emerging industries. At the same time, most scholars rarely took the external political and economic environment of the firm into account, and there was a lack of research on the combining financing constraints with environmental factors such as economic policy uncertainty and institutional environment. In fact, technological innovation depends to a large extent on the amount of external financing that a company obtains. Economic policy uncertainty and institutional environment both affect the company's external financing environment and then affect the company's financing constraints, and ultimately affect the company's technological innovation activity.

\section{Research Hypotheses}

Arrow believed that technological innovations have externalities, showing spillover effects and diffusion effects, which make technological innovation show strong nonexclusive and limited exclusivity. The diffusion of externalities enables the competitors to acquire technology at a lower cost than innovators in order to improve their productivity and innovation [34]. The enterprises undertaking technological innovation burden the high cost, but they fail to access all the benefits. Under the spillover effect of technological innovation, some of the profits are occupied by other enterprises, so the enterprises are less motivated to engage in technological innovation and even have the idea of free rider.

According to the theory of net present value, the principle of optimal investment decision is that marginal revenue equals marginal cost. Financing constraints disable the enterprise to make optimal investment decisions and inhibit technological innovation. There are two main reasons. One reason is that, due to the limited internal funds, external financing is required. However, companies will weigh the cost of financing and their benefits [35]. Once the company faces financing constraints, the cost of external funds will be higher than the cost of internal funds, which increases the cost of technological innovation. When such investment cost increases to the present value of the project's expected cash flow, the enterprise may cease its investment in technological innovation, thus delaying the innovation project that could have been implemented. The other reason is the difficulty of external financing, which prevents enterprises from obtaining the funds they need. Then, even if the marginal revenue of an enterprise is greater than its marginal cost, technological innovation projects cannot be implemented due to capital constraints.

It can be seen that, under the influence of the external characteristics of technological innovation, enterprises' willingness to undertake technological innovation is not high. When the financing constraints become tighter, the enterprise's investment cost in technological innovation will increase correspondingly. Then, the willingness of enterprises to undertake technological innovation activities will also decline. Therefore, Hypothesis 1 is put forward.
Hypothesis 1. Financing constraints negatively affect the technological innovation. In other words, financing constraints have an inhibitory effect on the enterprise's technological innovation.

Strategic emerging industries consist of nine subindustries. Since the characteristics of financing constraints and technological innovation vary in different industries, the impact of financing constraints on technological innovation must be different to some extent in certain industries. Therefore, Hypothesis 2 is put forward.

Hypothesis 2. The influence of financing constraint on different subindustries of strategic emerging industries is different.

Due to the great difference between the output of the manufacturing industry and that of the nonmanufacturing industry, there are different characteristics in innovation. The manufacturing industry is dominated by technological innovation, while the nonmanufacturing industry is dominated by service innovations, such as organizational innovation, normative innovation, and characteristic innovation. These service innovations have little to do with technological innovation. Meanwhile, the strategic position of technological innovation in enterprises also varies greatly. Yuan pointed out that there is an obvious difference in the dependence of the manufacturing industry and service industry on $\mathrm{R} \& \mathrm{D}$. The manufacturing industry has a relatively large investment in technological innovation, and $R \& D$ investment plays a decisive role. Many companies even have set up specialized $R \& D$ departments, while the service industry has a smaller dependence on $R \& D$, and the investment in technological innovation is far lower than that of the manufacturing industry [36]. Therefore, the manufacturing industry has a strong desire to improve the productivity of enterprises through technological innovation. It can then be inferred that the inhibitory effect of financing constraints on the manufacturing industry is smaller than that on the nonmanufacturing industry. Therefore, Hypothesis 3 is put forward.

Hypothesis 3. The negative impact of financing constraint on manufacturing industry is less than that on nonmanufacturing industry.

Rajan and Zingales constructed the industry's external financing dependence, which was used to measure the industry's dependence on external funds, and they analyzed 36 industries in US industrial companies [10]. They came to a conclusion that traditional industries generally rely less on external financing while emerging industries mostly rely more on external financing. The top three industries with the highest external financing dependence are drugs and pharmaceuticals, plastics, and computing. The three industries with the lowest external financing dependence are the tobacco, pottery manufacturing, and leather industries. According to the definition and scope of strategic emerging industries in China, it can be found that most strategic 
emerging industries are highly dependent on external financings, such as the new generation of the information technology industry and the biomedical industry. Based on the industry's external financing dependence, we put forward the following expectations: the deterioration of the financing environment will have a greater impact on the computer industry and other industries with higher external financing dependence than those with low dependence on external financing. Therefore, Hypothesis 4 is put forward.

Hypothesis 4. The negative impact of financing constraints on the industries with low external financing dependence is less than that on the industries with medium- and high-level external financing dependence.

For general investment, scholars generally believe that the economic policy uncertainty inhibits enterprises' investment, but technological innovation differs from general investment, and thus, the impact of economic policy uncertainty may vary correspondingly. Technological innovations are full of high uncertainty, which also means that there are many market opportunities in the future. It is the source of future profits for enterprises. The future profit opportunities will disappear if these uncertainties are removed while enterprises pursue high profits. Uncertainty will stimulate their innovation behaviors and encourage entrepreneurs to pursue greater profits. From this perspective, the uncertainty of economic policy means not only risks and challenges but also opportunities and benefits. For entrepreneurs with an innovative spirit, they will make full use of the opportunities brought by the economic policy uncertainty, avoid risks, create profits for enterprises, and enable the enterprises to develop and grow stronger. Furthermore, the adjustment cost of technical innovation is higher than that of physical capital investment [24]. Therefore, enterprises can save a lot of "adjustment costs" by keeping R\&D investment stable. Then, in the face of economic policy uncertainty, enterprises will tend to make use of the opportunities and keep the stable investment of technological innovation so that they can maintain continuous investment in technological innovation. Therefore, Hypothesis 5 is put forward.

Hypothesis 5. The restraining effect of financing constraints in periods of high economic policy uncertainty is less than that in periods of low economic policy uncertainty, that is, financing constraints have a more restraining effect on technological innovation in periods of low economic policy uncertainty.

Generally speaking, in the highly marketized regions, there are more mature and effective laws and regulations, less government interventions, a more effective financial system, and an open and transparent information disclosure, which provides a proper external political environment for technological innovation. As for the reasons, first, the market-oriented institutional environment helps to alleviate the information asymmetry between enterprises and investors, reduce the cost of external financing, and broaden the financing channels of enterprises, thereby optimizing the external financing structure of enterprises and making up for the lack of funds for technological innovation [37]. Second, the market-oriented system enhances the function of the market in resource allocation. It not only reduces the government's intervention and possibility of rent-seeking but also improves the specificity of innovation, stimulates the current $R \& D$ investment, and enhances the innovation initiative through a perfect patent protection system $(\mathrm{Wu}$ and Tang) [38]. Third, the market-oriented system can provide more sensitive price information for enterprises and make the capital flow to the sectors with high-efficiency investment, thereby improving the allocation efficiency of capital and reducing the distortion of capital price and the risk premium of capital to a certain extent. Fourth, the market-oriented system increases the labor remuneration of technical innovation personnel through income distribution and the rate of return on the technology of technical personnel, stimulates the innovation enthusiasm of technical personnel, and promotes the technological innovation. Fifth, the improvement of the market-oriented system can effectively promote China's foreign trade. Through the import and export of commodities, it is conducive to the introduction and absorption of technology by Chinese companies. Under the influence of technology spillover effects, it can promote innovation activities of Chinese enterprises ( $\mathrm{Li}$ and Liu) [33]. Therefore, the market-oriented institutional environment is conducive to alleviate the negative effect of financial constraints on technological innovation. Therefore, Hypothesis 6 is put forward.

Hypothesis 6. The restraining effect of financing constraints on technological innovation in high-market-oriented areas is less than that in low-market-oriented areas, that is, it has a more restraining effect on enterprises in low-market-oriented areas.

\section{Data and Methodology}

4.1. Model Specification. In order to test Hypothesis 1, we construct two models from the perspectives of input and output of technological innovation. The model of technological innovation input is as follows:

$$
\begin{aligned}
\text { Innovationg }_{i, t}= & { }_{0}+\alpha_{1} \text { Fconstraints }_{i, t-1}+\sum \theta_{i} x_{i, t-1} \\
& +\operatorname{ind}_{i, t}+\theta_{t}+\varepsilon_{i, t} .
\end{aligned}
$$

In view of the continuity of technological innovation activities, when setting the model in this study, explanatory variables and control variables will lag by one period (except the variable of company age). Innovationg ${ }_{i, t}$ represents the technological innovation input of the company $i$ in the year t. Fconstraints $s_{i, t-1}$ represents the variable of financing constraints, indicating the financing constraints of the company $i$ in the year $t-1 . \sum \theta_{i} x_{i, t-1}$ represents the vector combination of control variables. ind ${ }_{i, t}$ represents the industrial effect, $\theta_{t}$ represents the time effect, and $\varepsilon_{i, t}$ represents the comprehensive error.

Since the number of patent applications, which is the explained variable to measure the technological innovation output, is a discrete variable and does not necessarily meet 
the assumption of linear regression, we adopt the panel counting model. According to the distribution characteristics of the number of patent applications, there is a huge difference between the variance and the mean, and the variance is obviously greater than the mean. There may be excessive data dispersion, and it is difficult to satisfy Poisson regression condition that expectation and variance are equal. Therefore, the negative binomial regression model of panel data is adopted.

It is assumed that the number of patents filed by an enterprise is $Y_{i t}$ (the subscripted variable $i$ represents the enterprise observed, and the subscripted variable $t$ represents the year observed), and its conditional distribution function is as follows:

$$
P\left(Y_{i t}=y_{i t} \mid x_{i t}\right)=\frac{e^{-\lambda_{i t}} \lambda_{i t}^{y_{i t}}}{y_{i t} !}, \quad\left(y_{i t}=0,1,2, \ldots\right),
$$

where $\lambda_{i t}>0$ represents the average occurrence times of the event. In order to ensure that $\lambda_{i t}$ is a nonnegative figure, it is assumed that

$$
\lambda_{i t}=\exp \left(x_{i t}^{\prime} \beta+u_{i}\right)=\exp \left(x_{i t}^{\prime} \beta\right) \exp \left(u_{i}\right) \equiv v_{i} \exp \left(x_{i t}^{\prime} \beta\right),
$$

where $x_{i t}$ does not contain constant term. $v_{i} \equiv \exp \left(u_{i}\right)$ represents the individual effect in the form of product. In the case that it satisfies the condition that $v_{1}=v_{2}=\cdots v_{n}$, it means that there is no individual effect. More generally, the existence of individual effect is allowed. In other words, different individuals have different values of $v_{i}$. The probability density of the negative binomial regression model is

$$
f\left(Y_{i t} \mid \mu_{i t}, \alpha\right)=\frac{\Gamma\left(y_{i t}+\alpha^{-1}\right)}{\Gamma\left(y_{i t}+1\right) \Gamma\left(\alpha^{-1}\right)}\left(\frac{\alpha^{-1}}{\alpha^{-1}+\mu_{i t}}\right)^{\alpha^{-1}}\left(\frac{\mu_{i t}}{\alpha^{-1}+\mu_{i t}}\right)^{\alpha^{-1}}, \quad y_{i t}=0,1, \ldots
$$

where $\Gamma(\cdot)$ represents the gamma distribution function and $\alpha$ represents the overdispersion parameter. $E\left(Y_{i t} \mid x_{i t}\right)=\mu_{i t}$ and $\operatorname{Var}\left(Y_{i t} \mid x_{i t}\right)=\mu_{i t}+\alpha \mu_{i t}^{2}>\mu_{i t} . y_{i t}$ represent the number of patents applied by the enterprise $i$ in the year $t . \mu_{i t}$ represents the average value of the patents applied by the enterprise. After introducing relevant control variables, the negative binomial regression model of the technological innovation output is

$$
\mu_{i, t}=\exp \left(\alpha_{1} \text { Fconstraints }_{i, t-1}+\sum \theta_{i} x_{i, t-1}+\varepsilon_{i t}\right)
$$

To test Hypothesis 2 to Hypothesis 4, we group the samples according to their characteristics and compare the magnitude and significance of financing constraint coefficient. To test Hypothesis 5 and Hypothesis 6, we introduce economic policy uncertainty or marketization as the moderator based on model (1) and set the following econometric model:

$$
\begin{aligned}
& \text { Innovationg }_{i, t}=\alpha_{0}+\alpha_{1} \text { Fconstraints }_{i, t-1}+\sum \theta_{i} x_{i, t-1} \\
& +\alpha_{2} M_{i, t}+\alpha_{3} M_{i, t} \times \text { constraints }_{i, t-1}+\text { ind }_{i, t}+\theta_{t}+\varepsilon_{i, t},
\end{aligned}
$$

where $M_{i, t}$ represents the economic policy uncertainty or the marketization. If the estimate of the interaction coefficient $\alpha_{3}$ is significantly positive, the hypotheses $H_{5}$ and $H_{6}$ are supported. If $\alpha_{3}$ is significantly negative, it means the economic policy uncertainty or the marketization increases the negative effect of financing constraints on technological innovation.

\subsection{Variable}

4.2.1. Explained Variable. The explained variable is technical innovation. Technical innovation can be measured from the perspectives of input and output. For innovation input, we measure the company's technological innovation activities by the R\&D expense and use the R\&D concentration (the proportion of R\&D expenses to the total assets of the current period) and the R\&D intensity (the proportion of $\mathrm{R} \& \mathrm{D}$ expenses to current sales revenue). In terms of the technical innovation output, following Hall and Harhoff [39], we measure the output of technological innovation by the number of patent applications.

4.2.2. Explanatory Variable. The core explanatory variable is the financing constraints. Following Owen [40] to calculate $\mathrm{KZ}$ index and considering the characteristics of listed companies in China, the measurement method of FC index of the Chinese listed companies financing constraint is established. The first step is to classify the samples by year and calculate medians of the annual operating net cash flow (CF), cash dividends (DIV), cash holding/last term's assets (CashH), the leverage ratio (LEV), and Tobin's Q (TobinQ). Then, we assign a value to the variable. CF, DIV, and CashH are expected to be negative correlation with financing constraints, while LEV and TobinQ are positively correlated with financing constraints. The values are determined according to the following principles. If CF, DIV, and CashH are lower than their medians that year, the corresponding indicator value is taken as 1 ; otherwise, it is taken as 0 , expressed as $\mathrm{FC}_{1}, \mathrm{FC}_{2}$, and $\mathrm{FC}_{3}$. If LEV and TobinQ are higher than their medians that year, the corresponding indicator value is taken as 1 ; otherwise, it is taken as 0 , expressed as $\mathrm{FC}_{4}$ and $\mathrm{FC}_{5}$. The third step is to calculate the value of $\mathrm{FC}$, according to the equation $\mathrm{FC}=\mathrm{CF}_{1}+\mathrm{FC}_{2}$ $+\mathrm{FC}_{3}+\mathrm{FC}_{4}+\mathrm{FC}_{5}$. The fourth step is to use the panel sorting logistic regression model for regression. The dependent variable is $\mathrm{FC}$, and the explanatory variables are the original values of CF, DIV, CashH, LEV, and TobinQ. The regression 
coefficients of these explanatory variables are estimated, and the expression of the FC index is obtained. In the end, the actual values of CF, DIV, CashH, LEV, and TobinQ are substituted into the regression model, and the predicted FC value of the enterprise is calculated, which was the FC index of the enterprise. The higher the FC index is, the more serious financing constraints is.

According to the process above for calculating the FC index, the measurement result of the financing constraints is $\mathrm{FC}=11.35 \mathrm{CF}-45.72 \mathrm{DIV}-4.04 \mathrm{CashH}+5.38 \mathrm{LEV}$

+0.16 TobinQ. Moreover, the regression coefficients of the five variables are all significant at the significance level of $1 \%$, and the overall significance of the model also passes the statistical test. It is illustrated that the five variables, namely, CF, DIV, CashH, LEV, and TobinQ, are the effective proxy variables affecting the financing constraints. In addition, $\mathrm{CF}$, DIV, and CashH are negatively correlated with financing constraints, while LEV and TobinQ are positively correlated with the financing constraints. It means that listed companies with high operating cash flow, high cash holding, high dividends, low leverage ratio, and low investment opportunities face less serious financing constraints. In contrast, listed companies with low operating cash flow, low cash holding, low dividends, high leverage ratio, and high investment opportunities face more severe financing constraints.

Two other important variables in this study are economic policy uncertainty and marketization. There are many measurement indicators of economic policy uncertainty. We adopt the economic policy uncertainty index constructed by Baker et al. [41]. This index has been widely used in recent macropolicy literature and has been proved to be comprehensive and objective to reflect the fluctuation of China's economic policy. Since the index is a monthly index, we use the monthly arithmetic average to convert the monthly economic policy uncertainty index into an annual economic policy uncertainty index. We use variable EPU to represent the economic uncertainty index. Marketization is mostly measured by the marketization index proposed by Fan et al., which consists of the relationship between the government and the market, the development of the nonstate economy, the development of the product market, the development of the factor market, and the development of market intermediary organizations [31]. The five aspects of the legal system environment can fully reflect all aspects of marketization. Therefore, marketization index is used to measure the level of marketization in each region. Since the sample in this article is data of listed companies in strategic emerging industries, it is not possible to directly obtain the corresponding market index of each listed company. The method is to find the market index of the corresponding province according to the province where each listed company is registered. We use marketization variable to represent the marketization index.

4.2.3. Control Variable. Control variables involved are Size representing the size of enterprises, Age representing the age of enterprises, TobinQ, Concentr representing equity concentration, Sgrowth representing the sales growth rate, and Cflow representing the cash flow ratio.

4.3. The Data. Our samples are the companies listed on the main board of China in strategic emerging enterprise from over 2009 to 2019. As there are no strategic emerging industries in the industry classification of the China Securities Regulatory Commission, it is impossible to obtain the sample of listed companies of strategic emerging industries directly. In order to gather the samples of listed companies in strategic emerging industries, the following steps are followed.The initial sample is selected from the sample stocks of China Strategic Emerging Industries Composite Index ("Emerging Composite Index") released by China Securities Index Co., Ltd., and Shanghai Stock Exchange in 2017, covering a total of 1117 companies listed as A-shares in Shanghai and Shenzhen Stock Exchanges, on the SMEs board (Small and Medium Enterprise Board), the secondboard market, and the new OTC market (new over-thecounter market). Due to the small amount of data disclosed by listed companies on the new OTC market and the poor comparability compared with other listed companies, such companies are removed from the sample frame. Next, some filter conditions are set in the sample frame. The ST and $*$ ST listed companies within the sample period are deleted. Then, the listed companies in the financial and insurance industry are deleted. At last, the samples with missing values of some indexes are deleted. After the steps detailed above, the final samples are 757 listed companies in the strategic emerging industries over the period of 2009 to 2019.

\section{Empirical Results and Discussions}

5.1. The Inhibitory Effect of Financing Constraints. We focus on the impact of financing constraints on technical innovation. Columns 2 and 3 of Table 1 report the impact of financing constraints on technological innovation input. As shown in Table 1, financing constraints negatively affect the concentration and intensity of R\&D at the significance level of $5 \%$. That is, financing constraints inhibit technological innovation input. For listed companies, technological innovation is a very important investment decision for enterprises, involving large capital investment and a long time of capital occupation. When enterprises face serious financing constraints, their internal and external funds cannot meet the capital demand for technological innovation, so enterprises' technological innovation activities will be postponed.

The impact of financing constraints on technological innovation output is also vital. According He and Zhang [42] and $\mathrm{Li}$ and Zheng [43], the patent applications for measuring the technological innovation are divided into two types. One is the substantive innovation with a higher technological level represented by invention patents, aiming to promote social and technological progress and occupy a competitive advantage in the industry. Andrea pointed out that financing constraints have a significant negative effect on fundamental innovation [44]. The other is strategic innovations with low 
TABLE 1: Regression results of the influence of financing constraints on technical innovation.

\begin{tabular}{|c|c|c|c|c|c|}
\hline Variable & $\begin{array}{c}\mathrm{R} \& \mathrm{D} \\
\text { concentration }\end{array}$ & $\begin{array}{c}\mathrm{R} \& \mathrm{D} \\
\text { intensity }\end{array}$ & $\begin{array}{l}\text { Number of patent } \\
\text { applications }\end{array}$ & $\begin{array}{c}\text { Number of invention } \\
\text { patents }\end{array}$ & $\begin{array}{c}\text { Number of noninvention } \\
\text { patents }\end{array}$ \\
\hline L.FC & $\begin{array}{c}-0.031^{* *} \\
(0.014)\end{array}$ & $\begin{array}{c}-0.114^{* * *} \\
(0.032)\end{array}$ & $\begin{array}{r}-0.024^{*} \\
(0.012)\end{array}$ & $\begin{array}{c}-0.038^{* *} \\
(0.015)\end{array}$ & $\begin{array}{l}-0.002 \\
(0.014)\end{array}$ \\
\hline L.size & $\begin{array}{l}-0.287^{* * *} \\
(0.051)\end{array}$ & $\begin{array}{c}-0.629^{* * *} \\
(0.119)\end{array}$ & $\begin{array}{c}0.357^{* * *} \\
(0.044)\end{array}$ & $\begin{array}{c}0.378^{* * *} \\
(0.050)\end{array}$ & $\begin{array}{c}0.348^{* * *} \\
(0.058)\end{array}$ \\
\hline L.TobinQ & $\begin{array}{l}-0.009 \\
(0.013)\end{array}$ & $\begin{array}{l}-0.029 \\
(0.029)\end{array}$ & $\begin{array}{c}0.024^{* * *} \\
(0.006)\end{array}$ & $\begin{array}{c}0.030^{* * *} \\
(0.010)\end{array}$ & $\begin{array}{c}0.009 \\
(0.010)\end{array}$ \\
\hline L.Concentr & $\begin{array}{c}-0.009^{* *} \\
(0.004)\end{array}$ & $\begin{array}{c}-0.025^{* * *} \\
(0.009)\end{array}$ & $\begin{array}{l}-0.000 \\
(0.003)\end{array}$ & $\begin{array}{c}0.002 \\
(0.003)\end{array}$ & $\begin{array}{c}0.002 \\
(0.003)\end{array}$ \\
\hline L.Sgrowth & $\begin{array}{l}-0.011 \\
(0.024)\end{array}$ & $\begin{array}{c}-0.165^{* * *} \\
(0.054)\end{array}$ & $\begin{array}{l}-0.000 \\
(0.000)\end{array}$ & $\begin{array}{l}-0.000 \\
(0.000)\end{array}$ & $\begin{array}{c}0.000 \\
(0.000)\end{array}$ \\
\hline Age & $\begin{array}{c}-0.037^{* *} \\
(0.015)\end{array}$ & $\begin{array}{c}-0.160^{* * *} \\
(0.036)\end{array}$ & $\begin{array}{c}0.045^{* * *} \\
(0.011)\end{array}$ & $\begin{array}{c}0.071^{* * *} \\
(0.010)\end{array}$ & $\begin{array}{l}0.024^{*} \\
(0.014)\end{array}$ \\
\hline L.Cflow & & & $\begin{array}{c}-0.003^{* *} \\
(0.002)\end{array}$ & $\begin{array}{c}-0.005^{* *} \\
(0.002)\end{array}$ & $\begin{array}{l}-0.000 \\
(0.002)\end{array}$ \\
\hline Constant & $\begin{array}{c}9.033^{* * *} \\
(1.203)\end{array}$ & $\begin{array}{c}17.980^{* * *} \\
(2.798)\end{array}$ & $\begin{array}{c}-7.436^{* * *} \\
(0.922)\end{array}$ & $\begin{array}{c}-8.479^{* * *} \\
(1.058)\end{array}$ & $\begin{array}{c}-7.302^{* * *} \\
(1.203)\end{array}$ \\
\hline $\begin{array}{l}\text { Time effect } \\
\text { Industry } \\
\text { effect }\end{array}$ & $\begin{array}{l}\text { Controlled } \\
\text { Controlled }\end{array}$ & $\begin{array}{l}\text { Controlled } \\
\text { Controlled }\end{array}$ & & & \\
\hline Sample size & 757 & 757 & 628 & 625 & 608 \\
\hline
\end{tabular}

Notes: ${ }^{* * *},{ }^{* *}$, and ${ }^{*}$ mean significant at the significance level of $1 \%, 5 \%$, and $10 \%$, respectively. The figures in parentheses are standard errors, the same as below. L.variables represent variables with a lag of one period.

technical level represented by utility model patents and design patents, most of which aim to obtain other benefits. Then the influence of financing constraints on the different types of patent applications is studied. Columns 4 to 6 of Table 2, respectively, report the impact of financing constraints on the number of patent applications, invention applications, and noninvention applications. In order to determine whether negative binomial regression is a fixed effect or a random effect, the Hausmann test is carried out. The results show that the $p$ value is less than 0.01 , which strongly rejected the negative binomial regression of random effect. Therefore, the fixed-effect negative binomial regression is adopted. Hilbe pointed out that, in the counting model, the marginal effect of variables is more significant than that of the regression coefficient [45]. We use the marginal effect to analyze the impact of the unit change of the explanatory variable on the explained variable. Columns 4 and 5 of Table 1 show that, in terms of both the number of patent applications and the number of invention patents, financing constraints inhibit technological innovation output at the significance level of $10 \%$. Column 6 of Table 1 shows that the influence of financing constraints on the number of nonpatent applications is negative but not significant. The above results indicate that therestraint of financing constraints on the inventionpatent is greater than that of noninvention patent, mainly because of the different nature of the two types of patents. The invention patent can improve the production efficiency of enterprises, enable enterprises to obtain competitive advantages in the industry, and represent the core competitiveness of enterprises. However, invention patents usually require a lot of investment and last a long time before they come out.
On the contrary, the purpose of noninvention patents is to echo the innovation strategy of enterprises and national innovation policies, and the companies pay more attention to the "speed" and "quantity" of innovation. Noninvention patents involve a relatively small investment, a relatively short duration cycle, and a relatively little influence by capital. Due to the essential differences between invention patents and noninvention patents, enterprises have different attitudes towards the two kinds of patents, which ultimately leads to the difference in the degree of influence of financing constraints on the two kinds of patents. This conclusion is consistent with Khan et al. [46].

The results above indicate that financing constraints not only inhibit the technological innovation input in emerging industries but also inhibit the technological innovation output of the enterprise in emerging industries, and thus, Hypothesis 1 has been supported.

\subsection{The Heterogeneous Influence of Financing Constraints}

5.2.1. Analysis by Industry. Considering that different subindustries in strategic emerging industries have different characteristics of financing constraints and technological innovation, the sensitivity of technical innovation to financing constraints may be heterogeneous. We further analyze by industry in order to find out the difference in the impact of financial constraints on technical innovation of various subindustries in strategic emerging industries. Since there are many subindustries in the strategic emerging industries, only R\&D intensity is used as the explained variable to analyze by industry. 
TABLE 2: Regression analysis of different subindustries in strategic emerging industries.

\begin{tabular}{lccccccc}
\hline Variable & $\begin{array}{c}\text { Next-generation } \\
\text { information } \\
\text { technology }\end{array}$ & $\begin{array}{c}\text { Advanced } \\
\text { equipment } \\
\text { manufacturing }\end{array}$ & $\begin{array}{c}\text { New } \\
\text { material } \\
\text { industry }\end{array}$ & $\begin{array}{c}\text { Biological } \\
\text { industry }\end{array}$ & $\begin{array}{c}\text { New energy } \\
\text { automobile } \\
\text { industry }\end{array}$ & $\begin{array}{c}\text { New } \\
\text { energy } \\
\text { industry }\end{array}$ & $\begin{array}{c}\text { Environmental } \\
\text { protection industry }\end{array}$ \\
\hline L.FC & $-0.238^{* * *}$ & $-0.084^{*}$ & -0.011 & 0.211 & $-0.126^{*}$ & 0.178 & -0.005 \\
$(0.066)$ & -0.049 & $(0.039)$ & $(0.170)$ & $(0.073)$ & $-143)$ & $(0.041)$ \\
\hline L.size & -0.098 & $-0.586^{* * *}$ & $-0.642^{* * *}$ & -0.579 & -0.065 & -0.077 & $-1.002^{* * *}$ \\
$(0.161)$ & $(0.136)$ & $(0.723)$ & $(0.211)$ & $(0.212)$ & $(0.204)$ \\
\hline \multirow{2}{*}{ L.TobinQ } & $(0.273)$ & 0.002 & $0.082^{*}$ & 0.004 & 0.037 & $1.011^{* *}$ & $-0.263^{* * *}$ \\
\hline \multirow{2}{*}{ L.Concentr } & 0.025 & $(0.060)$ & $(0.042)$ & $(0.149)$ & $(0.134)$ & $(0.496)$ & $(0.058)$ \\
\hline \multirow{2}{*}{ L.Sgrowth } & $(0.054)$ & $-0.025^{* *}$ & 0.008 & -0.075 & -0.008 & 0.006 & 0.009 \\
& $(0.021$ & $(0.012)$ & $(0.009)$ & $(0.055)$ & $(0.014)$ & $(0.013)$ & $(0.008)$ \\
\hline \multirow{2}{*}{ Age } & $0.009^{* * *}$ & -0.000 & $0.006^{* * *}$ & -0.002 & -0.001 & 0.008 & -0.001 \\
& $(0.002)$ & $(0.001)$ & $(0.002)$ & $(0.007)$ & $(0.003)$ & $(0.006)$ & $(0.001)$ \\
\hline Sample size & $-0.276^{* * *}$ & $-0.096^{*}$ & 0.020 & -0.249 & -0.036 & 0.041 & $-0.071^{*}$ \\
\hline
\end{tabular}

Notes: according to the Guiding Catalogue of Key Products and Services for Strategic Emerging Industries (2016 Edition) issued by the National Development and Reform Commission in 2017, the strategic emerging industries are divided into nine sectors (including related service industries). Considering the small number of samples of digital cultural and creative industries and related service industries, they are not separately analyzed by industry.

Columns 2 to 8 of Table 2 report the effects of financing constraints in different subindustries in strategic emerging industries on technological innovation. It is found that there are pronounced industry differences in the impact of financing constraints on technological innovation. Except for the biological industry and new energy industry, the impact of financing constraints on technological innovation investment in the other five industries is uniformly negative. In the new generation information technology industry, advanced equipment manufacturing and new energy vehicle industry with high R\&D intensity, the negative impact is statistically significant, but not in the new material industry and energy conservation and environmental protection industry with relatively low R\&D intensity. This is because the higher the R\&D intensity is, the more the money for R\&D investment will be, and the stronger the influence of financing constraints will be. In the regression analysis of the biological industry and the new energy industry, the financing constraints' coefficient is not negative. The main reason is that these two industries are industries with relatively small financing constraints and are less affected by financial factors. Therefore, financing constraints have no obvious inhibitory effect on technological innovation, and thus, Hypothesis 2 has been verified.

5.2.2. Whether It Is a Manufacturing Enterprise. We divide the listed companies in strategic emerging industries into manufacturing and nonmanufacturing industries according to the classification standards of China's high-tech industries. The regression results of Table 3 show that the inhibitory effect of the financing constraints on the technological innovation input and output of the manufacturing industry is lower than that of the nonmanufacturing industry. The possible reason is that China's labor costs have risen sharply, which has seriously affected the operating profits of enterprises in the labor-intensive and capital-intensive manufacturing industries. Therefore, the manufacturing industry is more willing to improve labor productivity through technological innovation, and technological innovation is of greater significance to manufacturing enterprises. Manufacturing companies invest more in $\mathrm{R} \& \mathrm{D}$ and have a longer cycle for capital recovery. Once the technical innovation project is launched, the funds need to be continually invested. Otherwise, the invested cost will become a sunk cost and cannot be recovered. The characteristic of high adjustment cost of R\&D input is more obvious in the manufacturing industry, and manufacturing enterprises will pay more attention to the sustainability of R\&D. Therefore, technological innovation will not react so sensitively to the capital situation. Even if the financing constraints are intensified, the technological innovation in the manufacturing industry will not be reduced rapidly but need a long time to adjust. However, nonmanufacturing industries are mostly asset-light enterprises, which involve relatively less investment in technological innovation, with low $\mathrm{R} \& \mathrm{D}$ intensity and less dependence on technological innovation. Therefore, in these enterprises, technological innovation is more sensitive to the financial situation, and thus, Hypothesis 3 has been verified.

\subsubsection{Level of the Dependence of Industry External Financing.} The companies are divided into two groups according to the external financing dependence in the industry to test whether the inhibitory effect of financing constraints on technological innovation is related to the external financing dependence of the industry. One group are the companies with low external financing dependence and the other are the companies with medium- and high-level external financing dependence. The grouping results of the sample in Table 4 show that only a few strategic emerging enterprises 
TABLE 3: The classification test results of manufacturing enterprises and nonmanufacturing ones.

\begin{tabular}{lcccccc}
\hline \multirow{2}{*}{ Variable } & \multicolumn{2}{c}{ R\&D concentration } & \multicolumn{2}{c}{ R\&D intensity } & \multicolumn{2}{c}{ Number of patent applications } \\
& Manufacturing & Nonmanufacturing & Manufacturing & Nonmanufacturing & Manufacturing & Nonmanufacturing \\
\hline \multirow{2}{*}{ L.FC } & -0.015 & $-0.094^{* *}$ & $-0.100^{* * *}$ & $-0.151^{* *}$ & $-0.021^{*}$ & $-0.061^{*}$ \\
& $(0.012)$ & $(0.043)$ & $(0.035)$ & $(0.075)$ & $(0.012)$ & $(0.034)$ \\
\hline All controls & Controlled & Controlled & Controlled & Controlled & Controlled & Controlled \\
Sample size & 543 & 214 & 543 & 214 & 484 & 144 \\
\hline
\end{tabular}

TABle 4: The classification test result of the level of the external financing dependence in the industry.

\begin{tabular}{|c|c|c|c|c|c|c|}
\hline \multirow[b]{2}{*}{ Variable } & \multicolumn{2}{|c|}{ R\&D concentration } & \multicolumn{2}{|c|}{ R\&D intensity } & \multicolumn{2}{|c|}{ Number of patent applications } \\
\hline & $\begin{array}{l}\text { Low external } \\
\text { financing } \\
\text { dependence }\end{array}$ & $\begin{array}{l}\text { Medium- and high- } \\
\text { level external } \\
\text { financing dependence }\end{array}$ & $\begin{array}{l}\text { Low external } \\
\text { financing } \\
\text { dependence }\end{array}$ & $\begin{array}{l}\text { Medium- and high- } \\
\text { level external } \\
\text { financing dependence }\end{array}$ & $\begin{array}{l}\text { Low external } \\
\text { financing } \\
\text { dependence }\end{array}$ & $\begin{array}{l}\text { Medium- and high- } \\
\text { level external } \\
\text { financing dependence }\end{array}$ \\
\hline L.FC & $\begin{array}{c}0.107 \\
(0.113)\end{array}$ & $\begin{array}{c}-0.034^{* *} \\
(0.014)\end{array}$ & $\begin{array}{l}-0.060 \\
(0.117)\end{array}$ & $\begin{array}{c}-0.116^{* * *} \\
(0.033)\end{array}$ & $\begin{array}{l}-0.003 \\
(0.088)\end{array}$ & $\begin{array}{c}-0.021^{*} \\
(0.013)\end{array}$ \\
\hline $\begin{array}{l}\text { All } \\
\text { controls }\end{array}$ & Controlled & Controlled & Controlled & Controlled & Controlled & Controlled \\
\hline $\begin{array}{l}\text { Sample } \\
\text { size }\end{array}$ & 14 & 743 & 14 & 743 & 14 & 614 \\
\hline
\end{tabular}

are in the industries with low-level external financing dependence, with only 14 samples, accounting for $1.9 \%$ of the total samples. It indicates that most enterprises in the strategic emerging enterprises are in the industries with high external financing dependence. The regression results in Table 4 show that the negative effect of financing constraints on the technical innovation input and output is not significant in the samples of industries with low external financing dependence. However, in the industry with medium- and high-level external financing dependence, the impact of financing constraints on the technical innovation's input and output is significant at the $10 \%$ significance level, and thus, Hypothesis 4 has been verified.

\subsection{The Moderating Effect of the External Environment}

5.3.1. The Economic Uncertainty as the Moderator. As an external factor affecting enterprises' technological innovation, economic policy has an impact on the technological innovation activities of enterprises from a macroperspective. Once a country's economic policy changes, enterprises' innovation activities will inevitably be affected by the policy.

Columns 2 and 3 in Table 5 are the regression results after adding the cross terms of economic policy uncertainty and financing constraints to the regression model. It shows that the negative effect of financing constraints on technological innovation is still significant, and the coefficient of the cross term is significantly positive, indicating that economic policy uncertainty alleviates the inhibitory effect of financing constraints on technological innovation. Specifically, when the uncertainty of the economic policy environment increases, the inhibitory effect of financing constraints on the technological innovation input may be reduced. There are two main explanations. On the one hand, the increasing uncertainty of economic policy means that enterprises' business environment will change significantly.
TABLE 5: The moderating effect of economic policy uncertainty.

\begin{tabular}{|c|c|c|}
\hline Variable & R\&D concentration & R\&D intensity \\
\hline L.FC & $-0.069^{* * *}(0.026)$ & $-0.286^{* * *}(0.060)$ \\
\hline L.size & $-0.273^{* * *}(0.050)$ & $-0.592^{* * *}(0.120)$ \\
\hline L.TobinQ & & $-0.022(0.029)$ \\
\hline L.Concertr & $-0.009^{* *}(0.004)$ & $-0.025^{* * *}(0.009)$ \\
\hline L.Sgrowth & $-0.000(0.000)$ & $-0.002^{* * *}(0.001)$ \\
\hline Age & $-0.037^{* *}(0.015)$ & $-0.160^{* * *}(0.036)$ \\
\hline EPU* L.FC & $0.000^{*}(0.000)$ & $0.001^{* * *}(0.000)$ \\
\hline EPU & $0.003^{* * *}(0.001)$ & $0.013^{* * *}(0.002)$ \\
\hline Constant & $8.409^{* * *}(1.162)$ & $15.80^{* * *}(2.775)$ \\
\hline Sample size & 757 & 757 \\
\hline
\end{tabular}

This is both an opportunity and a challenge, and the survival of the fittest among enterprises will be presented. Only those enterprises with high production efficiency and strong competitiveness can finally survive in the industry. Furthermore, innovation ability is the key factor for enterprises to enhance their core competitiveness. Enterprises can make use of the opportunities brought by the economic policy uncertainty and improve their core competitiveness by increasing the input in technological innovation activities so as to boost their chances of winning in the future market competition. On the other hand, the uncertainty of economic policies will then spread to the external financing market, leading to the fluctuation of the capital market, and then affect the external financing of technological innovation. According to the research of Li and Yang [47], it can be seen that the economic policy uncertainty inhibits general investment activities. Therefore, when economic policy uncertainty increases, ordinary investment activities will not be active, and there will be abundant capital in the capital market. However, technological innovation was fraught with uncertainty and the future is full of opportunities. When the economic policy uncertainty increases, financing for technological innovation is more likely compared with general 
investment activities. Therefore, economic policy uncertainty can ease the inhibitory effect of financing constraints on technological innovation, and thus, Hypothesis 5 has been verified.

5.3.2. The Marketization as the Moderator. Columns 2 and 3 in Table 6 are the regression results after adding the cross terms of marketization and financing constraints to the regression model. It shows that the coefficient of financing constraints is significantly negative, the coefficient of marketization is significantly positive, and the coefficient of a cross term is significantly positive, indicating that the marketization can help to alleviate the inhibitory effect of financing constraints on technological innovation. Specifically, when the market environment improves, the inhibitory effect of financing constraints on technological innovation will be reduced. Therefore, the more the marketoriented, the lower the inhibitory effect of financing constraints on technological innovation and vice versa. In the end, the Matthew effect occurs when the strong get stronger and the weak get weaker. Under such effect, the differences in technological innovation between regions are constantly widened. The possible explanation is as follows.In highly market-oriented regions, there are a sound legal system, high information transparency, a more robust financial system sound, and abundant financial resources. Such a perfect institutional environment can ease the enterprise's financing constraints, provide a proper external financing environment for technological innovation, and better escort the enterprise's technological innovation, which is conducive to encourage enterprises to carry out technological innovation. In regions with less market-oriented, it is impossible to provide a strong institutional guarantee for technological innovation. For an enterprise facing financing constraints, this adverse institutional environment intensifies the inhibitory effect of financing constraints on technological innovation and is not conducive to the enterprise's technological innovation, and thus, Hypothesis 6 has been verified.

\subsection{Robustness Test}

5.4.1. Solutions to Endogenous Problems. Financial constraints inhibit enterprises' technological innovation activities, and technological innovation may make financial constraints of enterprises get more serious, thus leading to a bidirectional causal relationship between financial constraints and technical innovation. In order to avoid possible reverse causality, all control variables and the explanatory variables are delayed by one period. Simultaneously in the study, to avoid the endogenous problems caused by the omitted variables, the industry and time fixed effects are controlled in the empirical analysis.

5.4.2. Recalculation of Financing Constraint Index. In the empirical analysis, we use the FC index to measure the financing constraints. However, there are various methods to measure the constraints with different emphases. In order to
TABLE 6: The moderating effect of the marketization.

\begin{tabular}{lcc}
\hline Variable & R\&D concentration & R\&D intensity \\
\hline L.FC & $-0.036^{* * *}(0.012)$ & $-0.168^{* * *}(0.030)$ \\
Marketization & $0.838^{* * *}(0.266)$ & $1.319^{* *}(0.658)$ \\
Marketization ${ }^{*}$ L.FC & $0.017^{* *}(0.005)$ & $0.024^{*}(0.013)$ \\
All controls & Controlled & Controlled \\
Sample size & 757 & 757 \\
\hline
\end{tabular}

ensure robust conclusions, the SA index proposed by Hadlock and Pierce [48] is used to remeasure the financing constraints. That is, $\mathrm{SA}=-0.737$ Size +0.043 Size $^{2}$ -0.04 Age. The above empirical process is then repeated to check whether the financing constraints have an inhibitory effect on technological innovation.

The SA index is generally negative. The greater the absolute value of $\mathrm{SA}$ is, the more serious the financing constraints faced by the enterprise will be. Therefore, the SA index is negatively correlated with the level of financing constraints. The regression results in Table 7 show that the SA index is positively correlated with technological innovation at the significance level of 5\%, indicating the more serious the financing constraints is, the stronger the inhibitory effect on technological innovation activities will be. This is consistent with the conclusion of the test based on the FC index, which once again verifies that financing constraints have an inhibitory effect on technological innovation.

\subsubsection{Recalculation of the Technological Innovation Output.} The increment of intangible assets is adopted to remeasure the technological innovation output following Ju et al. [49]. Moreover, the ratio of the increment of intangible assets to the total assets at the end of the period is used as the proxy variable of the technological innovation output to remeasure the technological innovation output. Finally, the empirical results of the influence of financing constraints on the technological innovation output are shown in Table 8.

The results in Table 8 show that financing constraints have a significant inhibitory effect on the technological innovation output, regardless of if the FC index or SA index is used. It is consistent with the conclusion where the number of patent applications is adopted as the technological innovation output.

5.4.4. The Ordinary Panel Model as the Counting Model. The panel counting model is used to study the influence of financing constraints on the technical innovation output, which shows that financing constraints have a significant inhibitory effect on the technological innovation output. In order to test the robustness of the results, the number of patent applications as the explained variable is taken as a continuous common variable, and then the ordinary panel model is used for empirical analysis. The empirical results are shown in Table 9.

As shown in Table 9, the conclusion obtained using the ordinary panel model is that the financing constraints significantly inhibit the technological innovation output. After 
TABLE 7: Regression results of the impact of financing constraints on technological innovation through the SA index.

\begin{tabular}{lccc}
\hline Variable & R\&D concentration & R\&D intensity & Number of patent applications \\
\hline L.SA & $0.351^{* * *}(0.135)$ & $0.995^{* * *}(0.316)$ & $0.300^{*}(0.182)$ \\
L.LEV & $-0.444^{*}(0.240)$ & $-4.102^{* * *}(0.549)$ & $-0.003(0.002)$ \\
L.TobinQ & $0.003(0.013)$ & $-0.039(0.030)$ & $-0.005(0.012)$ \\
L.Concentr & $-0.010^{* *}(0.004)$ & $-0.020^{* *}(0.0098)$ & $-0.000(0.0037)$ \\
L.Cflow & $0.004^{*}(0.003)$ & $-0.004(0.006)$ & $0.002(0.006)$ \\
L.tangibility & $0.011^{* * *}(0.003)$ & $-0.118^{* *}(0.053)$ & $-9.301^{* * *}(1.361)$ \\
L.Sgrowth & $-0.011(0.023)$ & $5.283^{* * *}(1.360)$ & 628 \\
Constant & $2.159^{* * *}(0.592)$ & 757 & 6 \\
Sample size & 757 & &
\end{tabular}

TABLE 8: Robustness test results of intangible assets increment.

\begin{tabular}{lcc}
\hline Variable & FC index & SA index \\
\hline L.FC & $-0.042^{* *}(0.019)$ & $0.249^{* *}(0.108)$ \\
L.size & $0.000(0.041)$ & $0.037^{*}(0.019)$ \\
L.TobinQ & $0.039^{* *}(0.019)$ & $0.002(0.003)$ \\
L.Concentr & $0.000(0.003)$ & $-0.012^{* * *}(0.001)$ \\
L.Cflow & $-0.014^{* * *}(0.004)$ & $0.004(0.042)$ \\
L.Sgrowth & $-0.009(0.042)$ & $0.000(0.003)$ \\
Age & $-0.039^{* * *}(0.008)$ & $0.316(0.593)$ \\
L.tangibility & & 757 \\
Constant & $0.508(1.039)$ & 757 \\
Sample size & &
\end{tabular}

TABLE 9: Robustness test results of the ordinary panel model.

\begin{tabular}{lccc}
\hline Variable & Number of patent applications & Number of invention patents & Number of noninvention patents \\
\hline L.FC & $-0.045^{* * *}(0.012)$ & $-0.059^{* * *}(0.012)$ & $-0.028^{* *}(0.013)$ \\
L.TobinQ & $-0.003(0.008)$ & $0.002(0.008)$ & $-0.018^{* *}(0.009)$ \\
L.Concertr & $0.005^{* *}(0.002)$ & $0.004(0.003)$ & $0.006^{* *}(0.003)$ \\
L.Sgrowth & $-0.000(0.000)$ & $-0.000(0.000)$ & $-0.000(0.000)$ \\
L.lev & $0.017^{* * *}(0.002)$ & $0.017^{* * *}(0.002)$ & $0.016^{* * *}(0.002)$ \\
Age & $0.003(0.009)$ & $0.012(0.010)$ & $-0.004(0.010)$ \\
L.Cflow & $-0.004^{* *}(0.002)$ & $-0.005^{* * *}(0.002)$ & $-0.003(0.004)$ \\
Sample size & 691 & 691 & 691 \\
\hline
\end{tabular}

dividing the number of patent applications into invention patents and noninvention patents, we find that the inhibitory effect of the financing constraints on the invention patents is significantly higher than that of the noninvention patents, which is consistent with the conclusion obtained using the negative binomial regression model of panel data.

\section{Conclusions and Implications}

As the world economy enters a stage of innovation competition, the decision-making problem of technological innovation in emerging industries is a practical problem worthy of research and attention. Based on the panel data of the listed companies in China's strategic emerging industries from 2009 to 2019, we adopt the negative binomial regression model of panel data and empirically study the technological innovation decision-making issues of emerging industries from the perspective of financing constraints. Our results show that the financial constraints in strategic emerging industries in China significantly inhibit technological innovation in terms of technological innovation inputs and outputs. What is more, the inhibitory effect of substantive innovation like the invention patent is more pronounced than that of strategic innovation like the noninvention patent. The influence of financing constraints on technological innovation varies significantly between industries within strategic emerging industries, manufacturing industries and nonmanufacturing industries, and among industries with different external financing dependence. However, the economic policy uncertainty and the marketization can help to alleviate the inhibitory effect of financing constraints on technological innovation.

Our research conclusions lead to the following policy implications. First of all, the government should focus on solving the financial constraints by speeding up the reform of the financial system. Promoting the reform of the financial supply side, improving the efficiency of financial resource allocation, and reducing the financing cost should also be emphasized. In addition, it is necessary to expand the coverage of financial services, to develop financing platforms and tools exclusive to $R \& D$ intensive industries, such as strategic emerging industries, and to encourage venture capital and long-term capital to invest in technological 
innovation projects. A technological innovation financing system based on the market mechanism, guided by government investment, dominated by enterprises and widely participated by social funds, should be established. More financial resources can flow to technological innovation projects and to enterprises with technological innovation activities.

Second, at present, China's economy is in a "new normal" that requires innovation. In view of the selective effect of financing constraints on innovation activities, relevant departments should make effort to build a good external financing environment and use effective financial policies and administrative methods to help enterprises release their innovative vitality more fully. For example, relevant departments should pay attention to building a good marketoriented system and increase institutional guarantees for innovative activities, so as to improve the operating conditions of enterprises and promote high-quality innovative activities. When companies face financing constraints, these measures that are conducive to improving operating conditions will help to stimulate innovation.

Finally, since the financing constraints have a more obvious restraining effect on enterprises' substantive innovation of high quality, the government should encourage enterprises to increase $R \& D$ investment in substantive innovation [50-53], while guiding them to pursue high-quality innovation, so as to avoid such innovations that emphasize only the quantity and speed. In addition, the government also should continue to increase financial investment in basic research for making up for the lack of substantive innovation of enterprises and aiming to truly improve innovation ability and quality of the enterprise.

\section{Data Availability}

The data used to support the findings of this study are available from the corresponding author upon request.

\section{Conflicts of Interest}

The authors declare that there are no conflicts of interest regarding the publication of this study.

\section{Acknowledgments}

This research was partly supported by the Natural Science Foundation of Zhejiang Province (Grant no. LQ19G030007) and Zhejiang Gongshang University Online and Offline Hybrid Teaching Reform Project (Grant no. 1010XJ2919103).

\section{References}

[1] H. Lei and W. Wang, "The impact of network structure on innovation efficiency: an agent-based study in the context of innovation networks," Complexity, vol. 21, no. 2, pp. 111-122, 2015.

[2] W. B. Arthur and W. Polak, "The evolution of technology within a simple computer model," Complexity, vol. 11, no. 5, pp. 23-31, 2010.
[3] J. J. Pang, G. Lin, R. L. Yang et al., "Promote continuous economic development. economic trends," Economic Dynamics, vol. 7, pp. 3-19, 2019.

[4] M. Cai and S. J. Liu, "The impact of government subsidies on the leverage ratio of strategic emerging industries," Contemporary Economic Research, vol. 8, pp. 90-100, 2020.

[5] J. R. Brown, S. M. Fazzari, and B. C. Petersen, "Financing innovation and growth: cash flow, external equity, and the 1990s R\&D boom," Journal of Finance, vol. 64, pp. 151-185, 2010.

[6] J. S. Ang, Y. Cheng, and C. Wu, "Does enforcement of intellectual property rights matter in China? evidence from financing and investment choices in the high-tech industry," Review of Economics and Statistics, vol. 96, no. 2, pp. 332-348, 2014.

[7] S. M. Fazzari, R. G. Hubbard, B. C. Petersen, A. S. Blinder, and J. M. Poterba, "Financing constraints and corporate investment," Brookings Papers on Economic Activity, vol. 1988, no. 1, 206 pages, 1988.

[8] T. Beck and R. Levine, "Industry growth and capital allocation:," Journal of Financial Economics, vol. 64, no. 2, pp. 147-180, 2002.

[9] M. Gertler and S. Gilchrist, "The role of credit market imperfections in the monetary transmission mechanism: arguments and evidence," The Scandinavian Journal of Economics, vol. 95, no. 1, pp. 43-64, 1993.

[10] R. G. Rajan and L. Zingales, "Financial dependence and growth," Social Science Electronic Publishing, vol. 88, no. 3, pp. 559-586, 1998.

[11] G. Borisova and J. R. Brown, "R\&D sensitivity to asset sale proceeds: new evidence on financing constraints and intangible investment," Journal of Banking \& Finance, vol. 37, no. 1, pp. 159-173, 2013.

[12] Y. S. Hwang, H. G. Min, and S. H. Han, "The influence of financial development on R\&D activity: cross-country evidence," Review of Pacific Basin Financial Markets \& Policies, vol. 13, no. 3, pp. 381-401, 2010.

[13] A. Hall, G. Bockett, S. Taylor, M. V. K. Sivamohan, and N. Clark, "Why research partnerships really matter: innovation theory, institutional arrangements and implications for developing new technology for the poor," World Development, vol. 29, no. 5, pp. 783-797, 2001.

[14] B. H. Hall, "Investment and research and development at the firm level: does the source of financing matter?" NBER Working Papers, 1992.

[15] C. P. Himmelberg and B. C. Petersen, "R\&D and internal finance: a panel study of small firms in high-tech industries," The Review of Economics and Statistics, vol. 76, pp. 38-51, 1994.

[16] Z. He and M. B. Wintoki, "The cost of innovation: R\&D and high cash holdings in US firms," Journal of Corporate Finance, vol. 41, pp. 280-303, 2016.

[17] B. Mulkay, B. H. Hall, and J. Mairesse, Firm Level Investment and R\&D in France and the United States: A comparison, Social Science Electronic Publishing, Berlin, Germany, 2001.

[18] D. Harhoff, Are there financing constraints for R\&D and investment in German manufacturing firms? The Economics and Econometrics of Innovation, Springer, Berlin, Germany, 2000.

[19] S. Bond and D. H. V. Harhoff, "Investment, R\&D and financial constraints in Britain and Germany," Annales d'Économie et de Statistique, vol. 79/80, pp. 433-460, 2005.

[20] C. Bloch, "R\&D investment and internal finance: the cash flow effect," Economics of Innovation and New Technology, vol. 14, no. 3, pp. 213-223, 2005. 
[21] G. Scellato, "Patents, firm size and financial constraints: an empirical analysis for a panel of Italian manufacturing firms," Cambridge Journal of Economics, vol. 31, pp. 55-76, 2007.

[22] E. Ughetto, "Does internal finance matter for R\&D? new evidence from a panel of Italian firms," Cambridge Journal of Economics, vol. 32, no. 6, pp. 907-925, 2008.

[23] D. Czarnitzki and H. Hottenrott, "R\&D investment and financing constraints of small and medium-sized firms," Small Business Economics, vol. 36, no. 1, pp. 65-83, 2011.

[24] B. H. Hall, "The financing of research and development," Oxford Review of Economic Policy, vol. 18, no. 1, pp. 35-51, 2002.

[25] J. R. Brown and B. C. Petersen, "Cash holdings and R\&D smoothing," Journal of Corporate Finance, vol. 17, no. 3, pp. 694-709, 2011.

[26] D. Li, "Financial constraints, R\&D investment, and stock returns," Review of Financial Studies, vol. 24, no. 9, pp. 2974-3007, 2011.

[27] A. Mina, H. Lahr, and A. Hughes, "The demand and supply of external finance for innovative firms," Industrial and Corporate Change, vol. 22, no. 4, pp. 869-901, 2013.

[28] X. Gu, Y. Chen, and S. Pan, "Economic policy uncertainty and innovation: evidence from listed companies in China," Review of Financial Studies, vol. 2, pp. 109-123, 2018.

[29] F. Knight, Risk, Uncertainty and Profit, Houghton Mifflin Company, Boston, MA, USA, 1921.

[30] W. Hao, W. Wei, and J. Wen, "How does economic policy uncertainty affect corporate innovation-perspective of mechanism of action of real option theory," Economic Management, vol. 38, pp. 40-54, 2016.

[31] G. Fan, X. Wang, and G. Ma, "The contribution of China's marketization process to economic growth," Economic Research, vol. 46, no. 9, pp. 4-16, 2011.

[32] K. Z. Dai and Y. J. Liu, "The impact of marketization reform on R\&D investment in China's high-tech industry," Science Studies, vol. 31, pp. 50-57, 2013.

[33] P. Li and X. Liu, "The impact of market-oriented institutional change on China's technological progress-based on the perspective of independent R \& D and technology introduction," Economic Perspectives, vol. 4, pp. 42-50, 2015.

[34] K. J. Arrow, "Economic welfare and the allocation of resources for invention," The Rate and Direction of Inventive Activity, vol. 12, pp. 609-626, 1962.

[35] P. Kijkasiwat and P. Phuensane, "Innovation and firm performance: the moderating and mediating roles of firm size and small and medium enterprise finance," Journal of Risk and Financial Management, vol. 13, no. 5, p. 97, 2020.

[36] X. N. Yuan, "Manufacturing innovation and service innovation: comparison and convergence," Finance and Trade Research, vol. 20, pp. 14-19, 2009.

[37] Y. M. Zhu and M. E. Jia, "Marketization process, financial constraints and corporate technology innovation," Commercial ResearchInnovation Technology, vol. 1, pp. 49-56, 2017.

[38] C. P. Wu and D. Tang, "Intellectual property rights enforcement, corporate innovation and operating performance: evidence from China's listed companies," Economic Research Journal, vol. 51, no. 11, pp. 125-139, 2016.

[39] B. H. Hall and D. Harhoff, "Recent research on the economics of patents," Annual Review of Economics, vol. 4, pp. 541-565, 2012.

[40] L. Owen, P. Christopher, and J. Saaá-Requejo, "Financial constraints and stock returns," Review of Financial Studies, vol. 14, pp. 529-554, 2001.
[41] S. R. Baker, N. Bloom, and S. J. Davis, "Measuring economic policy uncertainty," The Quarterly Journal of Economics, vol. 131, no. 4, pp. 1593-1636, 2016.

[42] J. F. He and X. J. Zhang, "The influence of rising labor cost on enterprise innovation," The Journal of Quantitative \& Technical Economics, vol. 45, no. 8, pp. 56-73, 2018.

[43] W. J. Li and M. N. Zheng, "Is it substantive innovation or strategic innovation? - impact of macroeconomic policies on micro-enterprises' innovation," Economic Research Journal, vol. 4, pp. 60-73, 2016.

[44] C. Andrea, "Financing constraints, radical versus incremental innovation, and aggregate productivity," American Economic Journal: Macroeconomics, vol. 11, no. 2, pp. 75-309, 2019.

[45] J. M. Hilbe, Modeling Count Data, Cambridge University Press, Cambridge, UK, 2014.

[46] S. U. Khan, A. Shah, and M. F. Rizwan, "Do financing constraints matter for technological and non-technological innovation? a (re) examination of developing markets," Emerging Markets Finance and Trade, vol. 57, pp. 1-28, 2019.

[47] F. Y. Li and M. Z. Yang, "Can economic policy uncertainty influence corporate investment? the empirical research by using China economic policy uncertainty index," Journal of Financial Research, vol. 57, no. 9, pp. 2739-2766, 2015.

[48] C. J. Hadlock and J. R. Pierce, "New evidence on measuring financial constraints: moving beyond the KZ index," Review of Financial Studies, vol. 23, no. 5, pp. 1909-1940, 2010.

[49] X. S. Ju, D. Lu, and Y. H. Yu, "Financial constraints, working capital management, and the sustainability of firm innovation," Economic Research Journal, vol. 48, pp. 4-16, 2013.

[50] J. Li, J. Liang, V. Shi, and Q. Wang, "The benefit of manufacturer encroachment considering consumer's environmental awareness and product competition," Annals of Operation Research, vol. 3, pp. 1-19, 2021.

[51] J. Li, F. Wang, and Y. He, "Electric vehicle routing problem with battery swapping considering energy consumption and carbon emissions," Sustainability, vol. 12, no. 24, Article ID 10537, 2020.

[52] J. Li, L. Yi, V. Shi, and X. Chen, "Supplier encroachment strategy in the presence of retail strategic inventory: centralization or decentralization?" Omega, vol. 98, Article ID 102213, 2021

[53] J. Li, Z. Hu, V. Shi, and Q. Wang, "Manufacturer's encroachment strategy with substitutable green products," International Journal of Production Economics, vol. 235, Article ID 108102, 2021. 